\title{
Metacontingências e Autocontrole Ético: Efeito das magnitudes das consequências individuais e culturais
}

\section{Metacontingencies and Ethical Self-Control: Effect of magnitudes of individual and cultural consequences}

\author{
Bruno Rodrigues da Silva ${ }^{1, *}$ (D), Thais Maria Monteiro Guimarães ${ }^{1,2}$ (D, \\ \& Emmanuel Zagury Tourinho ${ }^{1}$ \\ ${ }^{1}$ Universidade Federal do Pará, Belém, Pará, Brasil \\ ${ }^{2}$ Beehave: Soluções Comportamentais, Juazeiro-Petrolina, Bahia-Pernambuco, Brasil
}

\begin{abstract}
RESUMO - O objetivo deste trabalho foi avaliar o efeito da manipulação das magnitudes das consequências individuais e culturais sobre o padrão de escolhas em situações de autocontrole ético e metacontingências. Seis estudantes universitários foram divididos em duas microculturas, uma com delineamento ABCAC'B'A e outra com um delineamento AC'B'ABCA. Nas condições B e B', a magnitude da consequência individual para respostas impulsivas aumentava enquanto a consequência cultural diminuía. Nas condições C e C', aumentava a magnitude da consequência cultural e diminuía a consequência individual. Os resultados indicaram a seleção de um padrão de escolhas em ambas as microculturas pela consequência cultural, com pouca ou nenhuma influência da manipulação da magnitude das consequências.
\end{abstract}

PALAVRAS-CHAVE: magnitude da consequência, autocontrole ético, metacontingência

\begin{abstract}
The objective of this study was to evaluate the effect of the magnitudes of the individual and cultural consequences on the pattern of choices in situations of ethical self-control and metacontingencies. Six college students were divided into two microcultures, one with ABCAC'B'A design and another with an AC'B'ABCA design. In conditions $\mathrm{B}$ and $\mathrm{B}$ ' the magnitude of the individual consequence for impulsive responses increased while the cultural consequence diminished. In conditions $\mathrm{C}$ and $\mathrm{C}$ ' the magnitude of the cultural consequence increased and the individual consequence diminished. The results indicated the selection of a pattern of choices by the groups of both microcultures, according to the cultural consequence, with little or no influence of the manipulation of the magnitude of the consequences.
\end{abstract}

KEYWORDS: magnitude of the consequences, ethical self-control, metacontingency

A vida das pessoas é marcada desde o seu início por estar inserida em grupos nos quais outras pessoas constituirão fontes ubíquas de controle do comportamento do indivíduo. A vida em contexto social é se caracteriza pelo conflito entre contingências para o indivíduo e para os grupos dos quais o indivíduo faz parte. Esse conflito entre contingências se expressa na medida em que o comportamento do indivíduo pode resultar em consequências diferenciais para si próprio e para o grupo do qual faz parte. O estudo desse dilema social em Análise do Comportamento tem feito referência ao conceito de metacontingências e à noção de autocontrole ético (cf. Borba et al., 2017; Gomes \& Tourinho, 2016).
A metacontingência consiste em uma contingência de seleção cultural, atualmente entendida como a relação contingente entre um culturante que, por sua vez, consiste de uma unidade formada de contingências comportamentais entrelaçadas recorrentes e seus produtos agregados, e suas consequências selecionadoras referidas como consequências culturais (Glenn et al., 2016). As contingências comportamentais entrelaçadas envolvem contingências operantes, nas quais o comportamento de um indivíduo funciona como ambiente para o comportamento de outro(s), isto é, deve existir uma coordenação entre os comportamentos dos membros do grupo e o produto

\footnotetext{
*E-mail: brunorsilva87@gmail.com

- Submetido: 06/10/2017; Revisado: 25/03/2019; Aceito: 07/06/2019.
} 
agregado envolve os efeitos de seus comportamentos interrelacionados (Glenn, 2004). O culturante se assemelharia ao operante pelo fato de ambos consistirem em unidades do comportamento selecionadas pelo ambiente, com a diferença de que o operante se refere ao comportamento individual, enquanto o culturante é uma unidade que envolve o comportamento de mais de um organismo (Hunter, 2012). A consequência cultural consiste de um evento ou uma condição ambiental que possui efeito selecionador sobre o culturante (Glenn, 1988; Glenn et al., 2016), diferentemente das consequências individuais, cujo efeito se dá sobre o comportamento de um indivíduo em específico.

Alguns dos primeiros estudos empíricos a investigar a concorrência entre contingências individuais e culturais em metacontingências utilizaram do Jogo do Dilema do Prisioneiro Iterado como procedimento experimental (e.g. Costa et al., 2012; Ortu et al., 2012). O jogo Dilema do Prisioneiro Iterado envolve uma situação na qual dois ou mais participantes devem escolher entre uma resposta cooperativa e uma resposta competitiva, com consequências diferenciais para os participantes dependendo de sua escolha em relação à escolha de seus pares, em repetidos ciclos. Nesse procedimento, o participante recebe a maior consequência individual quando responde competitivamente, enquanto o outro (ou outros) responde( $\mathrm{m}$ ) cooperativamente; da mesma forma, o participante recebe a consequência individual menor quando responde cooperativamente e os demais respondem competitivamente. Quando mais de um participante escolhe a mesma resposta (cooperar ou competir), estes recebem ganhos intermediários, sendo que recebiam ganhos menores quando todos ou a maior parte dos participantes respondiam competitivamente, enquanto que seus ganhos eram maiores quando todos ou a maioria respondia cooperativamente. Quando a mesma quantidade de participantes fazia escolhas competitivas e cooperativas, as escolhas competitivas geravam ganhos maiores.

Esses estudos envolveram condições em que o grupo recebia consequências culturais diferentes por cooperar ou competir coordenadamente. A consequência cultural poderia implicar em acréscimos aos ganhos individuais quando todos (Ortu et al., 2012) ou quase todos os participantes (Costa et al.,2012) escolhiam a alternativa favorecida pela condição em vigor. A concorrência entre contingências individuais e culturais nesses estudos se davam na condição na qual todos ou a maioria dos participantes deveriam fazer a escolha competitiva, pois esta gerava ganhos individuais menores quando era escolhida pela maioria ou por todos os participantes.

$\mathrm{O}$ estudo de Costa et al. (2012) investigou o efeito das consequências individuais e culturais, bem como das interações verbais, sobre a coordenação de escolhas dos participantes. Os resultados sugeriram que a consequência cultural selecionou as contingências comportamentais entrelaçadas quando havia ou não possibilidade de comunicação entre os membros do grupo, inclusive quando resultava em consequências desvantajosas para o indivíduo. Adicionalmente, foi verificado que o comportamento verbal acelerou a frequência do culturante-alvo, como também produziu mudanças mais rápidas no padrão de escolhas individuais de acordo com as mudanças nas condições experimentais.

Ortu et al. (2012) também investigaram a seleção por uma consequência cultural e, entre outros objetivos, avaliaram o efeito da variação da magnitude da consequência cultural sobre a coordenação de escolhas do grupo. Os dados do estudo demonstraram que o aumento da magnitude da consequência cultural pode favorecer a seleção de culturantes e que, uma vez que o grupo adquire um desempenho estável, os efeitos tendem a se manter, ainda que a magnitude da consequência cultural diminua e que as contingências em vigor tenham produzido perdas em termos de consequências individuais.

Ainda que esses estudos envolvendo o Dilema do Prisioneiro não façam menção ao autocontrole ético, outras pesquisas (e.g. Borba et al., 2017; Gomes \& Tourinho, 2016) têm adotado essa noção para fazer referência ao padrão de comportamento mais favorável ao grupo em situações de concorrência entre contingências individuais e culturais. $\mathrm{O}$ autocontrole ético consiste em um repertório de autocontrole especificamente relacionado ao controle do comportamento individual que gera benefícios à cultura, frequentemente associado a perdas em termos de reforçadores ao nível individual (Tourinho \& Vichi, 2012).

$\mathrm{O}$ adjetivo ético, como aqui empregado, está relacionado a qualquer comportamento que beneficia a cultura (Borba, Tourinho, et al., 2014). No autocontrole ético, o indivíduo se comporta de modo a produzir consequências de menor magnitude para si em favor de produzir consequências mais favoráveis ao grupo, geralmente em longo prazo. Nessas situações, são consideradas respostas autocontroladas aquelas que produzem consequências tanto individuais quanto culturais, embora mais favoráveis à cultura e menos favoráveis ao indivíduo. Por sua vez, as respostas que produzem consequências mais favoráveis ao indivíduo são consideradas impulsivas (Borba, Silva, et al., 2014). Em alguns casos, o indivíduo pode não fazer contato direto com as consequências que beneficiam a cultura (Borba, Tourinho, et al., 2014). Nessas situações, o comportamento verbal pode constituir em uma variável de controle, funcionando como uma consequência mais imediata ao comportamento, ocasionalmente punindo o comportamento impulsivo (Borba, Silva, et al., 2014).

Pesquisas em metacontingências que investigaram o autocontrole ético (Borba et al., 2017; Gomes \& Tourinho, 2016) utilizaram como tarefa experimental a escolha de linhas, numeradas de 1 a 10 em uma matriz colorida. Nesse tipo de procedimento, escolhas em linhas ímpares produziam consequências individuais de maior magnitude, enquanto escolhas de linhas pares geravam consequências individuais de menor magnitude. Em condições que envolviam a 
concorrência entre contingências individuais e culturais, escolhas em linhas pares (respostas autocontroladas) possibilitavam a produção de consequências culturais quando os três participantes escolhiam linhas pares de cores diferentes. Por sua vez, escolhas em linhas ímpares (respostas impulsivas) por parte de pelo menos um dos participantes não produziam consequências culturais em condições de concorrência. No estudo de Gomes e Tourinho (2016), houve, adicionalmente, a manipulação da magnitude da consequência individual da resposta impulsiva pelo aumento progressivo da consequência. Ambos os estudos utilizaram uma consequência cultural de natureza diferente da consequência individual (fichas trocadas por dinheiro), que consistiu em itens escolares a serem doados para uma escola pública.

Os resultados de Borba et al. (2017) e Gomes e Tourinho (2016) demonstraram a efetividade da consequência cultural na seleção de culturantes em situação de concorrência entre a produção de consequências individuais de maior magnitude e uma consequência cultural de natureza diferente. Gomes e Tourinho (2016) verificaram ainda que a consequência cultural foi efetiva, inclusive em circunstâncias onde a coordenação de escolhas por parte dos membros do grupo comprometia a produção de consequências individuais de maior magnitude.

Os estudos que investigaram os efeitos da manipulação da magnitude ou da consequência cultural (Ortu et al., 2012) ou da consequência individual da resposta impulsiva (Gomes \& Tourinho, 2016) verificaram que o padrão de comportamento mais favorável ao grupo tendia a se manter, mesmo com a possibilidade de perdas em termos de ganhos individuais. Esses resultados permitem questionar se os membros de uma microcultura coordenariam o seu comportamento em função da consequência de maior magnitude, isto é, se poderiam mudar de um padrão de comportamento em favor do grupo (ou da cultura) para um comportamento em favor das consequências individuais, e vice-versa, de acordo com mudanças nas magnitudes das consequências individuais e culturais.

A manipulação da magnitude das consequências de forma inversa (aumentando uma e diminuindo outra) poderia ser uma forma de avaliar se a manipulação conjunta de consequências (individuais e culturais) afetaria o padrão de respostas dos membros de um grupo. Por exemplo, aumentar a magnitude da consequência cultural, enquanto se diminui a consequência individual da resposta impulsiva, poderia favorecer a seleção cultural na medida em que os participantes perderiam cada vez menos em termos de ganhos individuais alternativos? Por outro lado, aumentar a consequência individual da resposta impulsiva e diminuir a cultural poderia deixar os participantes menos propensos a coordenar seu comportamento, de modo a produzir a consequência cultural, uma vez que poderiam deixar de produzir um alto montante de consequências individuais?

Dessa forma, o presente estudo teve como objetivo avaliar o efeito da manipulação inversa e progressiva das magnitudes das consequências individuais e culturais sobre a seleção cultural e as respostas impulsivas e autocontroladas dos participantes. Um objetivo adicional consistiu em avaliar possíveis efeitos da história experimental, ao iniciar com manipulações que favoreçam ou o responder impulsivo ou o autocontrolado sobre manipulações posteriores que favoreçam o padrão oposto.

\section{MÉTODO}

\section{Participantes}

Participaram deste estudo seis estudantes de graduação, que compuseram dois grupos (microculturas) com três participantes cada. O recrutamento dos participantes se deu por contato prévio do pesquisador responsável e um auxiliar, que convidaram alunos do campus universitário no qual foi realizada a pesquisa, solicitando meio de contato (e-mail, telefone) e disponibilidade de horário. As coletas eram marcadas quando se conseguia três participantes para o mesmo dia e horário.

\section{Ambiente Experimental e Materiais}

O local da pesquisa era composto por dois compartimentos (uma área de coleta e uma área de observação) separados por uma divisória com vidro peliculado que permite visão unidirecional. A área de coleta, onde ficaram o pesquisador, um auxiliar de pesquisa e os participantes, era equipada com uma mesa retangular, cadeiras estofadas e armários de madeira. O material utilizado incluiu um televisor de 42 polegadas, no qual foi projetada a matriz utilizada no estudo, além de três notebooks (um conectado ao televisor com a apresentação da matriz, outro com uma planilha para registro das escolhas dos participantes e um terceiro com webcam para a filmagem da coleta). Materiais adicionais incluíram fichas e tigelas de plástico para indicação das consequências individuais, um carimbo com carinha sorridente para registro das consequências culturais, folhas de papel e canetas à disposição dos participantes para anotações e itens escolares (cadernos, lápis, borrachas, etc.), que ficavam dispostos para a visualização dos participantes.

\section{Procedimento}

Tarefa. A tarefa neste estudo foi semelhante à utilizada por Borba et al. (2017) e Gomes e Tourinho (2016), que consistiu de escolhas em uma matriz de 10 linhas por 10 
colunas (Figura 1). As linhas da matriz eram numeradas de 1 a 10 e apresentavam uma dentre cinco cores (amarelo, verde, vermelho, azul e rosa). Cada cor aparecia em duas linhas, uma linha par e uma ímpar. As colunas eram identificadas com letras de A a J. Na interseção de cada linha com cada coluna poderia haver um círculo vazio ou um círculo preenchido.

$\mathrm{O}$ experimento era composto por ciclos. Durante o ciclo, o pesquisador solicitava um dos participantes a escolher uma linha da matriz. O participante deveria falar o número da linha em voz alta, de modo que o pesquisador pudesse ouvir a linha escolhida pelo participante. Após o participante escolher a linha, o pesquisador repetia a linha escolhida, como forma de confirmar a escolha do participante, informava a coluna escolhida pela programação da planilha utilizada no estudo e dava o feedback ao participante quanto aos pontos produzidos. Um auxiliar de pesquisa então depositava fichas em tigelas de plástico à frente do participante, de acordo com os pontos ganhos. $\mathrm{O}$ mesmo procedimento se repetia com os outros dois participantes. Se ao final das três escolhas fosse atingido o critério para a produção da consequência cultural, o auxiliar de pesquisa carimbava uma folha de registro específica, indicando o valor correspondente à consequência cultural produzida, e um novo ciclo se iniciava. Caso o critério para a consequência cultural não fosse atingido, igualmente um novo ciclo era iniciado.

A ordem em que os participantes eram solicitados a escolher uma linha variou ao longo dos ciclos. No primeiro ciclo, era estabelecida uma ordem na qual os participantes eram solicitados a escolher a linha, sendo definido um primeiro participante $(\mathrm{P} 1)$, um segundo $(\mathrm{P} 2)$ e um terceiro (P3). No segundo ciclo, as escolhas iniciavam com P2, que havia sido o segundo participante a escolher a linha no primeiro ciclo, sendo seguido pelos participantes P3 e P1, respectivamente. $\mathrm{O}$ terceiro ciclo iniciava com a escolha de P3, sendo seguido por P1 e, posteriormente, por P2. No quarto ciclo, a ordem de escolhas voltava a do primeiro

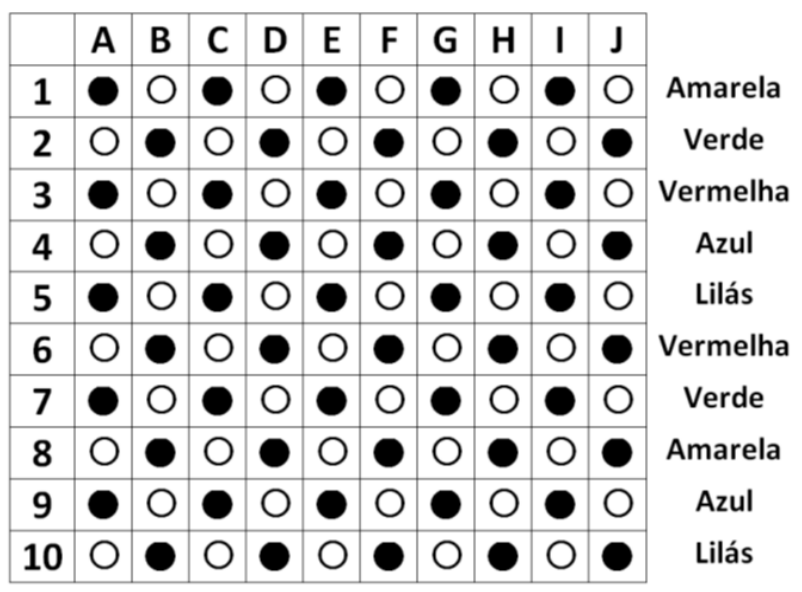

Figura 1. Matriz usada no estudo. ciclo (P1-P2-P3), seguidas nos ciclos seguintes pelas ordens do segundo (P2-P3-P1) e terceiro (P3-P1-P2) ciclos. Esse padrão de variação da ordem dos participantes ao longo dos ciclos se manteve até o fim do experimento com cada grupo de três participantes (microcultura). A variação na ordem de escolha dos participantes tinha como objetivo diminuir o seu efeito sobre o comportamento, favorecendo o controle pelas consequências e pelo comportamento de escolha dos demais participantes.

Contingências Operantes e Metacontingência. As consequências individuais consistiam de pontos representados por fichas plásticas depositadas em tigelas com etiquetas de 1, 10 e 100 pontos à frente de cada participante. A consequência individual de maior magnitude era contingente à escolha em linhas ímpares da matriz por parte dos participantes e tinha sua magnitude variável ao longo do experimento, podendo adquirir os valores de 2, 5, $10,20,40,80$ ou 160 pontos, de acordo com a condição do experimento. A consequência individual de menor magnitude era contingente a escolhas em linhas pares e tinha o valor fixo de 1 ponto ao longo de todo o experimento. $\mathrm{O}$ valor da consequência individual era indicado para o participante pela quantidade de fichas depositadas e pela tigela em que eram depositadas. Por exemplo, uma consequência de 1 ponto era indicada por 1 ficha na tigela com a etiqueta de 1 ponto, da mesma forma que 10 e 100 pontos eram indicadas por uma ficha em tigelas com etiquetas de 10 e 100 pontos. Outros valores eram indicados pelo depósito de diferentes números de fichas em uma ou mais tigelas de diferentes valores. Dessa forma, 2 pontos eram indicados por 2 fichas na tigela com etiqueta de 1 ponto, 20 pontos eram indicados por duas fichas na tigela de 10 pontos, 160 pontos eram indicados por 1 ficha na tigela de 100 pontos e 6 fichas na tigela de 10 pontos. Os pontos acumulados pelos participantes eram trocados por dinheiro ao final do experimento, na proporção de $\mathrm{R} \$ 0,01$ para cada 10 pontos. $\mathrm{Na}$ matriz, o tipo de consequência individual também era sinalizado pelo círculo na intersecção entre a linha escolhida pelo participante e a coluna apontada pela programação da planilha. $O$ círculo preenchido representava a consequência de maior magnitude e o círculo vazio, aquela de menor magnitude. Para isso, somente as colunas A, C, E, G e I da matriz foram programadas na planilha, portanto, somente elas eram informadas pelo pesquisador após a escolha da linha por cada participante.

A consequência cultural era denominada de bônus, representada por carimbos em uma folha de registro específica. A consequência cultural era liberada quando os três participantes escolhiam linhas pares de cores diferentes e sua magnitude também variou ao longo do experimento, assumindo os valores de 10, 20,30, 40, 50, 60 ou 70 bônus, de acordo com as condições experimentais. Os bônus acumulados ao longo do experimento foram trocados por itens escolares, na proporção 1 item para cada 10 bônus. Um item escolar tinha um valor médio de $\mathrm{R} \$ 0,15$ e poderia 
corresponder a qualquer material escolar (lápis, borrachas, cadernos, etc.). $\mathrm{O}$ valor total de itens era usado para a compra de materiais escolares diversos, que compunham um kit a ser doado pelos pesquisadores a uma escola pública.

As escolhas em linhas ímpares foram consideradas respostas impulsivas pois produziam consequências individuais de maior magnitude, mas não permitiam a produção de consequências culturais. As escolhas em linhas pares foram consideradas autocontroladas pois produziam consequências individuais de menor magnitude que poderiam produzir também uma consequência cultural, caso os três participantes escolhessem linhas pares de cores diferentes. Vale destacar que a matriz utilizada no estudo (ver Figura 1) era composta de 5 cores que se repetiam em duas linhas (par e ímpar), de modo que as únicas formas de diferentes participantes escolherem a mesma cor se dava quando ambos escolhiam uma linha de número par e de número ímpar da mesma cor (por exemplo, 2 e 7, que eram verdes) ou quando dois participantes escolhiam a mesma linha. $O$ fato de a escolha ser impulsiva ou autocontrolada e o valor das consequências individuais a elas atribuídas ao longo do experimento dependia unicamente de a linha escolhida pelo participante ser par ou ímpar, independentemente da cor da linha escolhida e das escolhas dos demais participantes. O critério da cor da linha só era levado em conta para a produção da consequência cultural, quando associado a escolhas em linhas pares. A concorrência entre consequências individuais e culturais se dava na medida em que para produzir consequências culturais os participantes deveriam escolher a opção que gerava menores ganhos individuais (linhas pares) em detrimento da opção que gerava mais ganhos individuais (linhas ímpares).

Instruções. Antes de iniciar o experimento, o pesquisador distribuiu uma folha com instruções iniciais (ver Apêndice A) a cada participante e leu junto com eles. Ao final da leitura das instruções iniciais, o pesquisador perguntava se os participantes tinham alguma dúvida. $\mathrm{O}$ pesquisador também avisava que, após recolher as instruções, não poderia tirar nenhuma dúvida a respeito do experimento. Não havendo dúvidas, as instruções eram recolhidas e o experimento iniciava.

Ao final da primeira Condição A e antes do início da condição seguinte em cada microcultura, foi apresentado um pedaço de papel a cada um dos três participantes com uma instrução complementar (ver Apêndice B). Após a leitura dessa pequena instrução, o pesquisador a recolhia e dava seguimento ao experimento. A função dessa pequena declaração era tornar os participantes mais sensíveis as mudanças nos valores das consequências individuais e culturais.

Delineamento Experimental. O estudo envolveu duas microculturas que apresentaram as seguintes condições experimentais: condições A, B, C, B' e C'. Cada condição tinha um número fixo de ciclos. As condições $\mathrm{A}, \mathrm{C}$ e B' eram compostas por 60 ciclos cada e as condições B e C' eram compostas por 90 ciclos cada. Em cada microcultura, a condição A ocorreu 3 vezes, o que, junto com as demais condições, gerou um total de 480 ciclos por microcultura. Durante a condição $\mathrm{A}$, as magnitudes das consequências individuais e culturais permaneceram fixas e funcionaram como base para manipulações das magnitudes em outras condições. As condições B e B' se caracterizaram pelo aumento da magnitude da consequência individual da resposta impulsiva (resultante de escolhas em linhas ímpares) e pela diminuição da magnitude da consequência cultural. As condições C e C', por sua vez, se caracterizaram pela diminuição da magnitude da consequência individual da resposta impulsiva e aumento da consequência cultural. A Tabela 1 apresenta os valores que as consequências individuais impulsivas e as consequências culturais assumiram em cada condição experimental.

Tabela 1

Magnitude da consequência individual da resposta impulsiva e da consequência cultural nas diferentes condições experimentais.

\begin{tabular}{ccc}
\hline Condição & $\begin{array}{c}\text { Consequência individual da } \\
\text { resposta impulsiva (Pontos) }\end{array}$ & $\begin{array}{c}\text { Consequência Cultural } \\
\text { (Bônus) }\end{array}$ \\
\hline A & 20 & 40 \\
& 40 & 30 \\
B & 80 & 20 \\
& 160 & 10 \\
C & 80 & 20 \\
& 40 & 30 \\
C' & 10 & 50 \\
& 5 & 60 \\
& 2 & 70 \\
B' & 5 & 60 \\
& 10 & 50 \\
\hline
\end{tabular}

O estudo foi composto de duas microculturas. A microcultura 1 apresentou um delineamento ABCAC'B'A. A microcultura iniciou com a condição $\mathrm{A}$, onde a magnitude da consequência individual da resposta impulsiva era de 20 pontos e a magnitude da consequência cultural era de 40 bônus. Após concluídos os 60 ciclos iniciais da condição A, iniciou-se a condição B. No início da condição $\mathrm{B}$, a magnitude da consequência individual da resposta impulsiva aumentou de 20 para 40 pontos e a consequência cultural diminuiu de 40 para 30 bônus. A cada 30 ciclos na condição $\mathrm{B}$, a consequência individual da resposta impulsiva dobrava, alcançando os valores de 80 pontos nos 30 ciclos seguintes e 160 pontos nos últimos 30 ciclos da condição. A consequência cultural na condição $\mathrm{B}$, por sua vez, diminuiu progressivamente com a subtração de 10 bônus a cada 30 ciclos, assumindo os valores de 20 bônus nos 30 ciclos seguintes e 10 bônus nos 30 ciclos finais. A condição $\mathrm{C}$ sucedia a condição $\mathrm{B}$. $\mathrm{Na}$ condição $\mathrm{C}$, a magnitude da consequência individual da resposta impulsiva diminuía 
e a da consequência cultural aumentava a cada 30 ciclos, retomando os valores de 80 e 40 pontos para a consequência individual e 20 e 30 bônus para a cultural. Uma nova condição A se seguiu, voltando a magnitude das consequências aos valores iniciais. Seguiram-se à segunda condição $\mathrm{A}$ as condições C' e B', nas quais as magnitudes também se alteravam a cada 30 ciclos. No entanto, na condição C', a consequência cultural aumentou, passando a atingir, respectivamente, os valores de 50, 60 e 70 bônus, enquanto a consequência individual da resposta impulsiva diminuía, atingindo os valores de 10, 5 e 2 pontos. Na condição B', os valores da consequência cultural voltavam a diminuir para 60 e, posteriormente, 50 bônus e a consequência individual da resposta impulsiva voltava a aumentar para 5 e 10 pontos. Após a condição B', uma terceira condição A encerrava o delineamento da microcultura 1.

As variações programadas nas magnitudes tinham como objetivo testar se as manipulações poderiam em algum momento favorecer a seleção operante (notadamente, quando aumentava-se a magnitude das consequências individuais enquanto diminuía-se a consequência cultural) ou favorecer a seleção cultural (aumentando-se a magnitude da consequência cultural e diminuindo-se a consequência individual), bem como verificar se um padrão de escolhas estabelecido poderia ser revertido. Além da microcultura 1, foi programada uma segunda microcultura. A microcultura 2 teve um delineamento AC'B'ABCA. As variações na magnitude das consequências em cada condição ocorreram da mesma forma que na microcultura 1, com a única diferença na ordem das condições. Essa segunda microcultura foi programada para avaliar possíveis efeitos da história experimental em comparação com a microcultura 1 . A microcultura 1 , que possuía um delineamento $\mathrm{ABCAC}$ 'B' $\mathrm{A}$, iniciava a manipulação das consequências com valores mais altos para a consequência individual da resposta impulsiva nas condições $\mathrm{B}$ e C, enquanto os valores da consequência cultural estariam mais baixos nas mesmas condições em relação as condições $\mathrm{A}$, que antecedia e sucedia as condições B e C. Esse arranjo de contingências poderia favorecer a seleção operante em detrimento da seleção cultural. Diferentemente disso, a microcultura 2, com o delineamento AC'B' $\mathrm{ABCA}$, iniciava a manipulação da magnitude das consequências com valores mais altos para a consequência cultural e mais baixos para a consequência individual da resposta impulsiva durante as condições C' e B' em relação a condição A, o que poderia favorecer mais a seleção cultural nesse caso. A partir dessas diferenças entre as duas microculturas, poderia se avaliar o efeito da ordem de exposição a essas diferentes condições sobre a seleção cultural, bem como sobre a mudança do padrão de respostas dos participantes (de impulsivo para autocontrolado e/ou vice-versa).

Análise de dados. Após a coleta com cada microcultura, foram selecionadas, da planilha utilizada para coleta os dados, as respostas impulsivas (escolhas de linhas ímpares) e às ocorrências do culturante-alvo (escolhas em linhas pares de cores diferentes) para a análise percentual de tais comportamentos, em blocos de 10 ciclos plotados nos gráficos. Contudo, as respostas autocontroladas (escolhas de linhas pares) também foram analisadas, uma vez que fazem parte do culturante-alvo.

Procedimentos éticos. Esta pesquisa foi avaliada e aprovada pelo Comitê de Ética em Pesquisa do Núcleo de Medicina Tropical da UFPA, sob o parecer de número 2.106.480. Todos os participantes leram e assinaram duas vias do Termo de Consentimento Livre e Esclarecido antes de iniciar a coleta de dados, ficando uma via com o participante e outra com o pesquisador.

\section{RESULTADOS}

A Figura 2 apresenta, na parte superior, a porcentagem de culturantes-alvo (escolhas de três linhas pares de cores diferentes) da microcultura 1 e, em seguida, a porcentagem de respostas impulsivas (escolhas em linhas ímpares) de cada um dos três participantes (P1, P2 e P3) da microcultura 1. A porcentagem foi medida em blocos de 10 ciclos, de modo que o primeiro ponto de cada linha corresponde à porcentagem entre os ciclos de 1 a 10 e os pontos seguintes representam os próximos intervalos de 10 ciclos. A percentagem representada por cada ponto indica a quantidade de ocorrências da resposta impulsiva ou do culturante-alvo naquele intervalo de 10 ciclos. Por exemplo, o primeiro ponto na curva de culturantes da Figura 2 indica uma taxa de $20 \%$, o que significa que nos ciclos de 1 a 10 da microcultura 1 houve duas ocorrências do culturante-alvo.

Durante a primeira condição A, houve poucas ocorrências do culturante-alvo, representadas no primeiro gráfico por porcentagem baixa nos primeiros 30 ciclos, no qual apenas quatro vezes foi atingido o critério para a consequência cultural. Ao longo do restante da condição $\mathrm{A}$, não houve produção do culturante-alvo, o que se estendeu por mais da metade da condição B. Apenas ao final da condição B, os participantes voltaram a produzir o culturante-alvo, cuja taxa cresceu progressivamente ao longo do final da condição. A partir da condição $\mathrm{C}$, os participantes da microcultura 1 passaram a produzir o culturante-alvo de forma mais consistente, com taxas iguais ou acima dos $60 \%$ e apenas algumas quedas pontuais na taxa do culturante.

A porcentagem de escolhas de linhas ímpares por parte dos participantes se mostrou bastante variável na condição A. P1 apresentou taxa de respostas impulsivas entre 20 e $90 \%$ das escolhas em intervalos de 10 ciclos. Semelhantemente a P1, o desempenho de $\mathrm{P} 2$ variou entre 20 e $80 \%$ e P3, entre 30 e $80 \%$ de respostas impulsivas a cada 10 ciclos. 


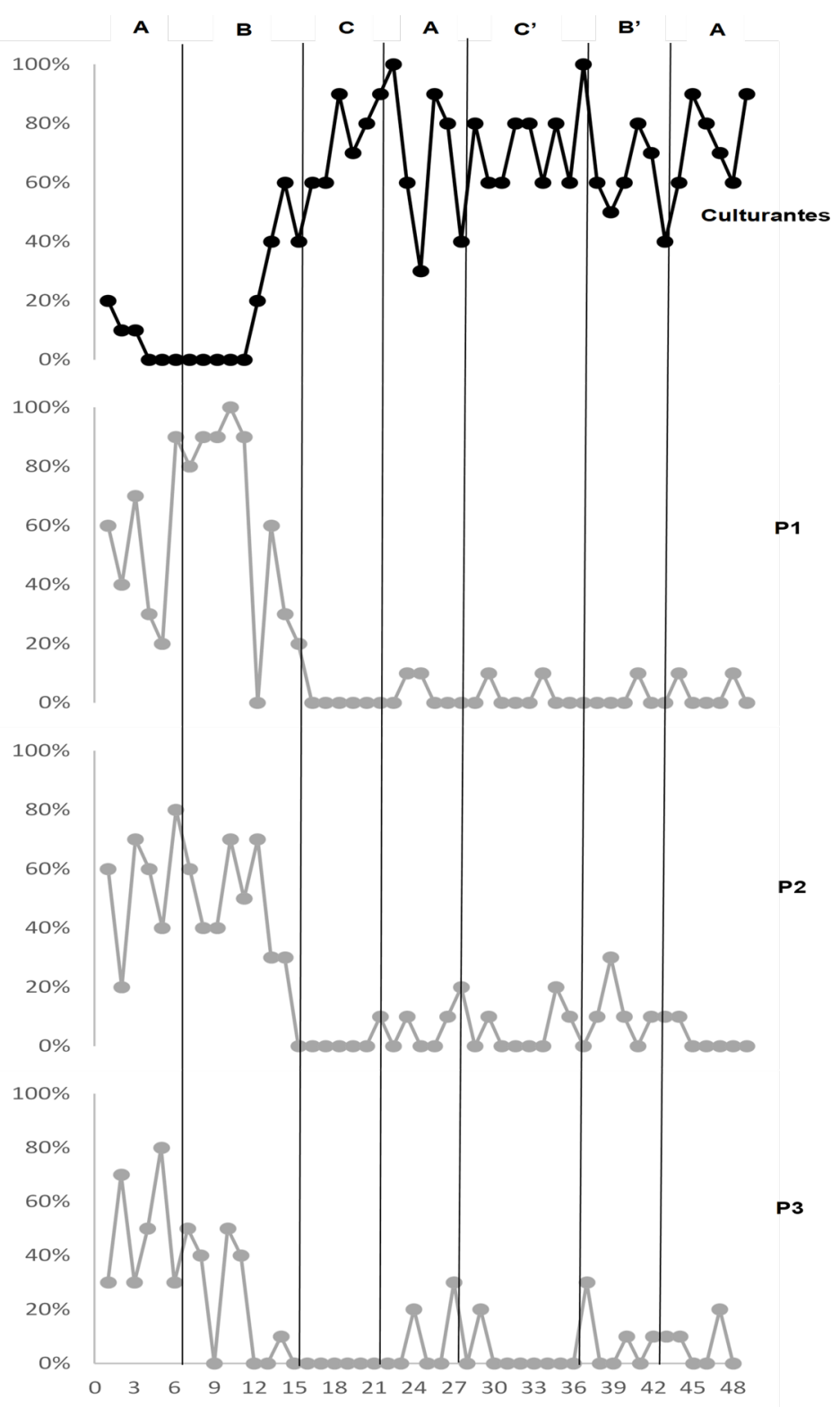

Figura 2. Porcentagem de culturantes e respostas impulsivas dos participantes da microcultura 1 em blocos de 10 ciclos.

Durante a condição B, a taxa de respostas impulsivas permaneceu muito variável, mas é possível verificar diferenças no desempenho dos participantes. P1 manteve uma alta taxa (igual ou maior que $80 \%$ ) de escolhas impulsivas nos primeiros 50 ciclos da condição $\mathrm{B}$, seguida de 13 ciclos de escolhas autocontroladas (linhas pares) que, por sua vez, foi seguida de um padrão alternado de escolhas impulsivas cada vez menos frequentes e escolhas autocontroladas cada vez mais frequentes. A proporção de escolhas impulsivas de $\mathrm{P} 2$ durante os primeiros 60 ciclos da condição $\mathrm{B}$ manteve-se semelhante à da condição $\mathrm{A}$, com taxas entre 40 e $70 \%$. Nos últimos 30 ciclos da condição $\mathrm{B}$, a porcentagem de escolhas impulsivas por parte de P2 também declinou. O participante $\mathrm{P} 3$ é o que apresenta as menores taxas de escolhas impulsivas que, desde o início da condição $\mathrm{B}$, não ultrapassam $50 \%$ de escolhas a cada 10 ciclos. Nos 40 últimos ciclos da condição B, P3 passa a emitir quase que unicamente escolhas autocontroladas, com apenas uma ocorrência de escolha impulsiva no ciclo 132.

A partir da condição $\mathrm{C}$, a taxa de respostas impulsivas permaneceu baixa ( 0 a $30 \%$ ) para todos os três participantes, com longos intervalos sem emissões de respostas impulsivas. Os dados das escolhas individuais são complementares aos dados da taxa do culturante-alvo. Se ao menos um participante escolhesse uma linha ímpar, isso impossibilitava a produção do culturante-alvo. Na condição A e durante a maior parte da condição $\mathrm{B}$, a ocorrência de respostas impulsivas foi acompanhada por poucas ocorrências do culturante-alvo. Por sua vez, a alta taxa de culturantes a partir da condição $\mathrm{C}$ indica menor ocorrência de respostas 
impulsivas, já que era necessário todos escolherem linhas pares.

A partir da segunda condição A e ao longo das demais condições (C', B' e a última condição A), manteve-se uma tendência alta de ocorrência de culturantes-alvo, frequentemente com percentuais iguais ou maiores que $60 \%$ ao longo de blocos de 10 ciclos. A taxa de produção de culturantes só ficou abaixo de $60 \%$ em alguns ciclos durante a segunda condição A e a condição B'. Em oposição a altas taxas do culturante-alvo, as taxas de respostas impulsivas por parte dos participantes tenderam a ser mais baixas entre a segunda e a última condição A. No entanto, houve uma pequena diferença entre os participantes, tendo $\mathrm{P} 1$ emitido menos respostas impulsivas que $\mathrm{P} 2$ e $\mathrm{P} 3$ ao longo da segunda metade da coleta com a microcultura 1 .

A Figura 3 apresenta as porcentagens a cada 10 ciclos de culturantes-alvo e respostas impulsivas dos participantes da microcultura 2. A condição A, assim como ocorreu com a

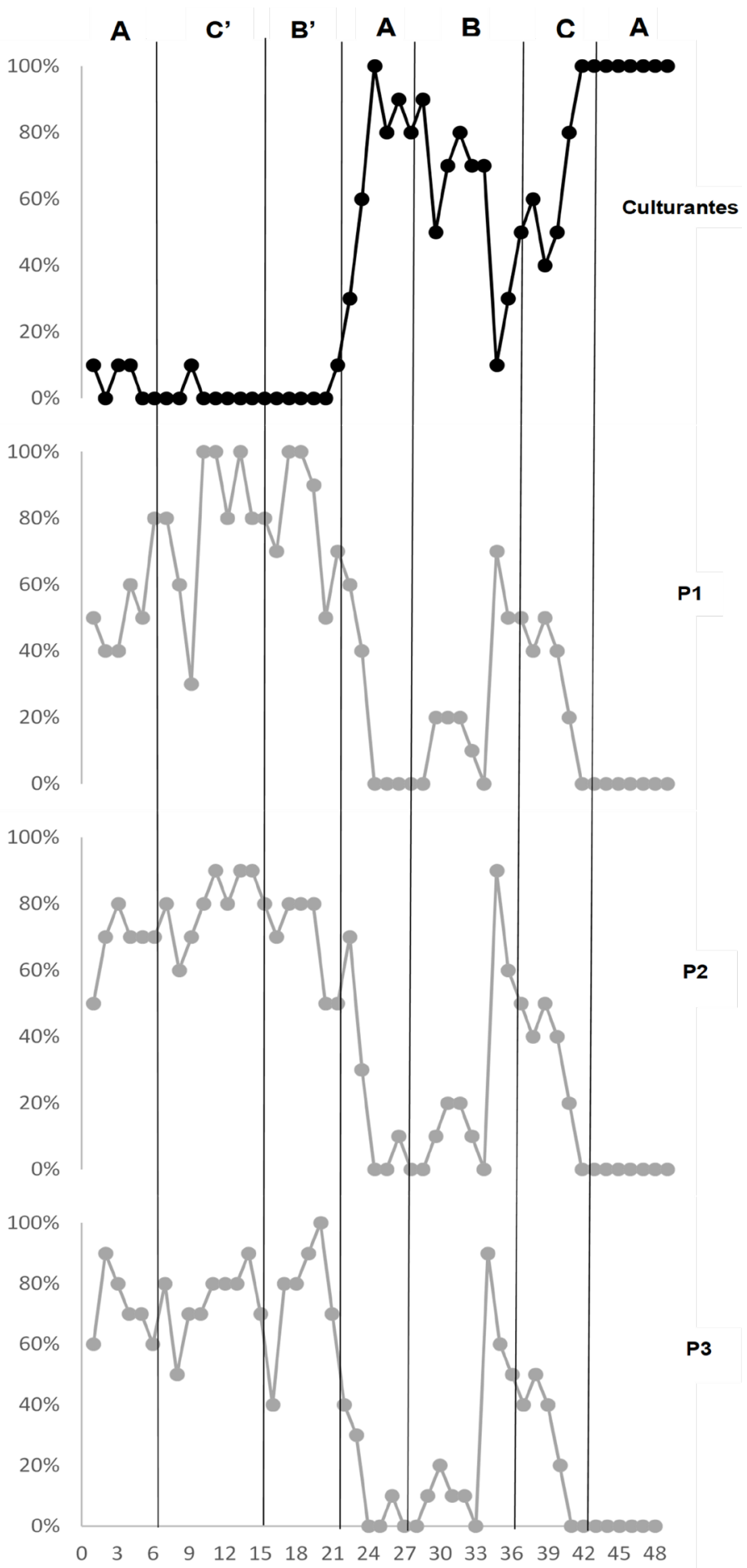

Figura 3. Porcentagem de culturantes e respostas impulsivas dos participantes da microcultura 2 em blocos de 10 ciclos 
microcultura 1, apresentou 3 ocorrências do culturante-alvo, seguida de vários ciclos sem a produção do culturante, $\mathrm{o}$ que se estendeu até o início da condição C'. As condições C' e B' apresentaram cada uma apenas uma ocorrência do culturante-alvo, com um intervalo de 123 ciclos sem ocorrência do culturante. Ao longo da segunda condição A, a taxa do culturante-alvo aumentou rapidamente: de $30 \%$ nos 10 ciclos iniciais a $100 \%$ no terceiro intervalo de 10 ciclos. A taxa do culturante-alvo permanece alta durante o restante da segunda condição A até os primeiros 10 ciclos da condição B. A partir daí, há uma redução de $90 \%$ para $50 \%$ na taxa de culturantes, que novamente sobe nos intervalos seguintes de 10 ciclos. Ao final da condição $\mathrm{B}$, quando a magnitude da consequência impulsiva atinge o valor mais alto (160 pontos) e a consequência cultural, o valor mais baixo (10 bônus), a taxa do culturante cai para o valor mais baixo (10\%) desde o início da segunda condição A. Nos 20 últimos ciclos da condição B e ao longo da condição $\mathrm{C}$, a taxa de culturante volta a aumentar progressivamente. Nos últimos 20 ciclos da condição $\mathrm{C}$, a taxa de produção de culturantes atinge novamente $100 \%$ e permanece assim até o fim do experimento.

$\mathrm{Na}$ microcultura 2, os dados das respostas impulsivas também complementam os dados do culturante-alvo. As taxas de respostas impulsivas dos três participantes apresentaram uma grande variabilidade durante as três primeiras condições, onde quase não houve ocorrência do culturante-alvo. Frequentemente, a taxa de repostas impulsivas esteve acima dos $60 \%$ para os três participantes. A taxa de respostas impulsivas começa a cair sobretudo a partir da segunda condição A, quando a taxa do culturante, por sua vez, aumenta. A taxa de respostas impulsivas volta a aumentar no final da condição B e progressivamente cai ao longo do restante da condição B e da C. Ao final da condição $\mathrm{C}$, respostas impulsivas deixam de ser emitidas.

\section{DISCUSSÃO}

Os resultados de ambas microculturas demonstraram a seleção de um padrão específico de coordenação das escolhas dos participantes (no caso, escolha de três linhas pares de cores diferentes), por uma consequência cultural de natureza diferente da consequência individual em situação de concorrência entre a produção de consequências culturais e consequências individuais. Esse resultado encontra-se em acordo com estudos anteriores (Borba et al., 2017; Gomes \& Tourinho, 2016), que verificaram a seleção cultural em condições semelhantes.

No entanto, a seleção do culturante-alvo parece ter sido dificultada pela concorrência entre contingências individuais (especificamente, a contingência operante impulsiva) e culturais. Gomes e Tourinho (2016) também identificaram uma menor efetividade do evento cultural na seleção e manutenção do culturante quando em comparação com situações sem concorrência.

A dificuldade na seleção do culturante em situações de concorrência pode ter sido influenciada também pela baixa probabilidade do culturante-alvo $(28,6 \%)$ em relação ao total de possibilidades de combinação de escolhas de cores entre os três participantes. Isso pode sugerir que a tarefa com a matriz na forma utilizada nesse estudo seria relativamente complexa, uma vez que exige dos participantes descobrir o critério para a produção do culturante-alvo e, sem a descoberta de tal critério, os participantes não seriam expostos consistentemente à manipulação programada para o estudo (variação da magnitude da consequência cultural). Futuros estudos que investiguem a influência da magnitude das consequências sobre a seleção cultural poderiam se utilizar de tarefas experimentais alternativas mais simples ou de uma versão simplificada da tarefa com a matriz utilizada no presente estudo.
Outro fator que dificultou a seleção do culturante pode ter decorrido da própria diferença das magnitudes de consequências individuais. Ambas as microculturas iniciavam com a condição A, na qual a resposta individual impulsiva (escolha em linha ímpar) produzia 20 pontos, enquanto a resposta individual autocontrolada (escolha em linha par) produzia apenas 1 ponto; ou seja, a resposta impulsiva gerava 20 vezes mais pontos que a autocontrolada. Essa diferença pode ter dificultado a seleção cultural, que dependia de escolhas em linhas pares. Novos estudos que investiguem o efeito da manipulação da magnitude das consequências sobre a seleção cultural em situação de concorrência podem utilizar uma diferença inicial menor entre consequências individuais impulsivas e autocontroladas.

Tanto a seleção quanto a manutenção da coordenação do comportamento dos membros de cada microcultura parecem não ter sido controlados pela variação das magnitudes das consequências programadas neste estudo. $\mathrm{O}$ único momento em que a variação das magnitudes das consequências parece ter exercido algum controle sobre o padrão de escolhas do grupo ocorreu nas condições $\mathrm{B}$ e $\mathrm{C}$ da microcultura 2. Após a seleção do culturante-alvo na condição A anterior, os membros dessa microcultura passaram a adotar um padrão no qual respondiam impulsivamente quando a consequência individual atingia seu valor máximo e a consequência cultural o mínimo durante alguns ciclos, seguido por um padrão alternado de respostas impulsivas e autocontroladas por alguns ciclos, com posterior retorno a um padrão exclusivo de respostas autocontroladas, a diminuição do valor da consequência individual e a recuperação do valor da consequência cultura. Esse dado sugere que, pelo menos durante um curto período, a seleção operante foi favorecida 
em relação à seleção cultural, com base na manipulação da magnitude das consequências.

A instalação e manutenção do culturante parece ter dependido mais das interações verbais entre os participantes, o que estaria de acordo com os resultados de Costa et al. (2012), que indicaram o efeito facilitador da comunicação na seleção cultural em situações de concorrência. A importância do comportamento verbal também tem sido citada em trabalhos teóricos como o de Glenn et al. (2016), quando afirmam que a maioria das contingências entrelaçadas constitutivas das metacontingências envolvem o comportamento verbal dos indivíduos participantes. Antes da coordenação do comportamento dos integrantes de cada microcultura promovida pela comunicação, cada um poderia estar respondendo independentemente das escolhas dos demais, não caracterizando um entrelaçamento de contingências. Os resultados de Soares et al. (2018) demonstraram que consequências culturais verbais (aprovação e desaprovação social) combinadas com consequências culturais não verbais (itens escolares) selecionaram e mantiveram culturantes em situação de concorrência entre contingências operantes e metacontingências de modo mais consistente, quando comparada com condições nas quais havia a manipulação separada desses dois tipos de consequência. Isso sugere que uma análise das interações verbais pode ser importante para identificar as variáveis relevantes em estudos de seleção cultural.

As microculturas 1 e 2 tiveram uma diferença em relação à seleção cultural na medida em que os participantes da microcultura 2 demoraram mais para produzir altas taxas do culturante-alvo. Essa diferença nos resultados das duas microculturas parece estar relacionada à variabilidade das respostas dos participantes. Na microcultura 1, na segunda condição (condição B), os participantes passaram a emitir cada vez mais respostas autocontroladas, sobretudo nos últimos 30 ciclos da condição $\mathrm{B}$, o que pode ter facilitado a ocorrência precoce do culturante-alvo. Já na microcultura 2, o padrão de responder impulsivo permaneceu estável durante as três primeiras condições (A, C' e B'), apesar de nas condições C'e B' os valores da consequência individual da resposta impulsiva serem os mais baixos, segundo o estabelecido no delineamento da microcultura 2. A baixa frequência de escolhas em linhas pares resultou em uma ocorrência tardia do culturante-alvo, em comparação com a da microcultura 1 .

O efeito da história experimental não pode ser aferido devido à seleção ter ocorrido em momentos distintos em cada microcultura. Ambas as microculturas foram expostas às mesmas condições, ainda que em diferentes ordens. No entanto, cada microcultura teve contato com as variações das magnitudes das consequências individuais e culturais de forma diferenciada. Enquanto os participantes da microcultura 2 já entraram na condição $\mathrm{B}$ com alta taxa de culturantes, os participantes da microcultura 1 começaram a produzir consistentemente o culturante nessa condição. Por outro lado, enquanto os participantes da microcultura 1 encontravam-se com taxas altas do culturante nas condições C'e B', na microcultura 2, nessas mesmas condições, quase não houve exposição dos participantes à consequência cultural e, portanto, não entraram em contato com a variação da magnitude da consequência cultural quando esta apresentou seus valores mais altos.

Talvez o modo como o procedimento foi executado neste estudo não tenha favorecido a avaliação dos efeitos das magnitudes sobre a seleção operante e cultural em concorrência, uma vez que a mudança das condições estava correlacionada ao cumprimento de uma quantidade predefinida de ciclos em vez de se basear no padrão de escolhas dos participantes. Uma mudança procedimental, que poderia ser aplicada em estudos posteriores, seria iniciar as manipulações das magnitudes das consequências após o grupo adquirir uma taxa estável na produção do culturante, se o objetivo for saber como essa manipulação pode afetar o padrão de respostas do grupo. A mesma alteração procedimental poderia ser utilizada em estudos que avaliassem a transmissão ao longo de gerações (substituição de participantes). Se o objetivo for verificar o efeito da magnitude sobre a seleção, seria possível comparar diferentes magnitudes da consequência cultural e/ou da consequência individual em diferentes grupos. Novos estudos poderão aferir melhor essa relação entre as magnitudes das consequências individuais e culturais sobre o desempenho dos indivíduos, em procedimentos com ou sem concorrência entre contingências individuais e culturais.

\section{REFERÊNCIAS}

Borba, A., Silva, B. R., Cabral, P. A. A., Souza, L. B., Leite, F. L., \& Tourinho, E. Z. (2014). Effects of exposure to macrocontingencies in isolation and social situations in the production of ethical self-control. Behavior and Social Issues, 23, 5-19. doi: 10.5210/bsi.v23i0.4237

Borba, A., Tourinho, E., \& Glenn, S. (2014). Establishing the macrobehavior of ethical self-control in an arrangement of macrocontingencies in two microcultures. Behavior and Social Issues, 23, 68-86. doi: 10.5210/bsi.v23i0.5354

Borba, A., Tourinho, E. Z., \& Glenn, S. S. (2017). Effects of cultural consequences on the interlocking behavioral contingencies of ethical self-control. The Psychological Record, 1-13. doi: 10.1007/s40732-017-0231-6

Costa, D., Nogueira, C. P. V., \& Vasconcelos, L. A. (2012). Effects of communication and cultural consequences on choices combinations in INPDG with four participants. Revista Latinoamericana de Psicología, 44(1), 121-131.

Glenn, S. S. (1988). Contingencies and metacontingencies: Toward a synthesis of behavior analysis and cultural materialism. The Behavior Analyst, 11, 161-179.

Glenn, S. S. (2004). Individual behavior, culture and social change. The Behavior Analyst, 27, 133-151. doi: 10.1007/bf03393175 
Glenn, S. S., Malott, M. E., Andery, M. A. P. A., Benvenuti, M., Houmanfar, R. A., Sandaker, I., Todorov, J. C., Tourinho, E. Z., \& Vasconcelos, L. A. (2016). Toward a consistent terminology in a behaviorist approach to cultural analysis. Behavior and Social Issues, 25, 11-27. doi: 10.5210/bsi. v25i0.6634

Gomes, H. C. R., \& Tourinho, E. Z. (2016). Metacontingências de autocontrole ético: Efeitos do aumento da magnitude de reforço. Psicologia: Teoria e Pesquisa, 32(4), 1-8.

Hunter, C. S. (2012). Analyzing behavioral and cultural selection contingencies. Revista Latinoamericana de Psicología, 44, 43-54.
Ortu, D., Becker, A. M., Woelz, T. A. R., \& Glenn, S. S. (2012). An iterated four-player Prisoner's Dilemma Game with an external selecting agent: A metacontingency experiment. Revista Latinoamericana de Psicología, 44, 111-120.

Soares, P. F. dos R., Rocha, A. P. M. C., Guimarães, T. M. M., Leite, F. L., Andery, M. A. P. A., \& Tourinho, E. Z. (2018). Effects of verbal and non-verbal cultural consequences on culturants. Behavior and Social Issues, 27, 31-46. doi: 10.5210/ bsi.v.27i0.8252

Tourinho, E. Z., \& Vichi, C. (2012). Behavioral-analytic research of cultural selection and the complexity of cultural phenomena. Revista Latinoamericana de Psicologia, 44, 169-179.

\section{APÊNDICE A}

\section{Instruções iniciais}

Vocês participarão de um estudo sobre comportamento de escolha em grupo. A tarefa de vocês será escolher, um de cada vez e quando solicitados pelo pesquisador, uma linha na matriz que se encontra exposta nesta TV. Cada um deverá informar, em voz alta, a linha escolhida, falando o número dela. Depois de realizada tal escolha, o computador irá selecionar aleatoriamente uma coluna para aquela jogada. Na interseção entre a linha escolhida por você e a coluna escolhida pelo computador pode haver um círculo preenchido ou vazio. Dependendo de qual símbolo for gerado, você poderá ganhar um ou mais pontos, que serão representados por fichas de cores diferentes $e$ depositadas nesses recipientes à frente de vocês. Ao final da participação, cada um de vocês poderá trocar pontos por dinheiro, de acordo com uma proporção pré-definida pelo pesquisador. Em determinados momentos, além de fichas, vocês poderão produzir bônus, que serão representados por carimbos nessas folhas que tenho à minha frente. Os bônus serão convertidos em itens escolares, segundo uma proporção também previamente definida pelo pesquisador, a serem doados a uma escola pública. Lembrem-se que as fichas produzidas e depositadas nos recipientes plásticos serão trocadas por dinheiro, que será pago a cada um de vocês individualmente ao final de sua participação no estudo, e que os bônus são trocáveis por itens escolares a serem doados para uma escola pública. Ao fim da sessão, o pesquisador ou um auxiliar estará à disposição dos participantes para explicar o procedimento e tirar dúvidas. Será solicitado, ao final da participação, o contato de cada um para informar sobre o dia e local da entrega dos itens escolares para que possam participar da doação, se assim desejarem. Durante o experimento, vocês terão folhas de papel em branco e canetas para fazer anotações e poderão conversar livremente.

\section{APÊNDICE B}

\section{Instrução complementar}

Atenção, a partir deste momento, a quantidade de pontos e bônus que vocês produzirem poderá variar. 